\title{
A PARTICIPAÇÃO \\ GUARANI MISSIONEIRA \\ NA VIDA COLONIAL RIO-PLATENSE
}

Eduardo Neumann*

O passado colonial, concernente às terras que integravam a Bacia Platina, costumeiramente foi retratado como o de uma sociedade estática, sem grandes acontecimentos, onde os trabalhos desenvolvidos não desvelavam seus executores.

A então Província do Paraguai, que compreendia as possessões meridionais hispano americanas, apresentou uma inserção distinta daquela vivenciada pelo Altiplano Boliviano e o Vale Mexicano; tanto pela inexistência de uma "riqueza" imediata, como pela presença de tradições indígenas em sua maioria nômades. Mas mesmo assim "(...) esta realidad que estudiamos, es parte integrante de un conjunto, el espacio peruano, cuya definición primera es la de ser una formación colonial". (Garavaglia, 1983 p. 382).

Esta sociedade contou com a forte presença da Igreja e de suas várias ordens religiosas, muitas empenhadas na conversão do gentio; trabalho levado a cabo tanto por franciscanos como jesuítas no Paraguai colonial.

O estabelecimento de "pueblos de indios" e de reduções foram uma das estratégias elaboradas através da "Leyes de Indias" para incorporar as várias tradições indígenas existentes ao longo do vasto Império colonial espanhol. Através deste expediente, foi possível por um lado preservar parte da população indígena de um etnocídio extremamente

* Mestre em História. Pesquisador do Programa Internacional de Investigações Interdisciplinares da Região Platina Oriental (PRÓPRATA).

Estudos Ibero-Americanos. PUCRS, v.XXI, n.1, p. 37-48, julho, 1995 
acelerado, e por outro arregimentar vários indígenas em um local previamente determinado.

Com o estabelecimento da Província Jesuítica do Paraguai, no início do século XVII, alicerçada neste "(...)prisma de três ângulos paraguai, guaranis e jesuítas - que a redução tomou uma coloração específica e diferenciada e se fez história singular" (Melia, 1989, p. 23).

Os resultados provenientes desta concatenação de realidades sociais, matizou colorações específicas para o desenvolvimento e inserção das terras paraguaias no Império Colonial Americano.

Os núcleos coloniais existentes em terras paraguaias, apresentavam-se com precariedade de instalações e oferta de serviços, mas mesmo assim "(...) llamadas por ellos ciudades, pero en realidad se parecen a humildes aldeas porque en la India ningun pueblo pasa por la humillación de llevar el nombre de aldea o villa" (Mühn, 1930, p. 264).

Estas "cidades de espanhóis" seguidamente enfrentavam dificuldades para suprir suas demandas por trabalhadores habilitados para a execução de uma série de "ofícios mecânicos, ${ }^{1}$ atividades necessárias e muitas vezes imprescindíveis a sobrevivência destes núcleos coloniais rio-platenses.

As reduções guarani, que floresceram entre os séculos XVII e XVIII, contrastavam com as "cidades de espanhóis", 2 tanto pela estrutura urbana das reduções, quanto pela organização e abastecimento interno das mesmas.

Uma leitura mesmo superficial da documentação referente ao passado histórico da sociedade colonial rioplatense, atesta que "(...) en general, una queja casi permanente se lee en actas del cabildo y en otros documentos, por falta de hombres de oficio (...)" (Adolfo, 1986, p. 165).

1 "Ofícios mecânicos": são as atividades manuais - principalmente as qualificadas onde a agricultura é excluída, tendo peso de destaque os artesãos, que conforme sua capacitação recebia o reconhecimento como oficial ou mestre. Esta expressão era utilizada pelas autoridade cabildantes portenhas para designar para designar os "(...) que se allan exercitados en los oficio mecânicos como son herreros, sapateros, sastres, carpinteros, galafates, albañiles, barberos (...)" in A.E.C.B.A., Série II, Tomo VII, 1928 , p. 472. Igualmente sob a designação de "oficio" compreendia-se tanto as arte mecânicas como qualquer ocupação habitual.

2 O Governador de Buenos Aires, manifstou-se desta maneira quanto ao progresso material das reduções, em contraste com as cidades espanholas "(...) dixo que ya no se admiraba de la embidia ñros emulos conta dhas Misiones donde se ve lo que no pueden conseguir los Españoles se sus ciudades de Indias" (Manuscritos, 1955, p. 180). 
Este fato era registrado em conseqüência de uma falta generalizada em todo Império colonial de trabalhadores e agricultores. ${ }^{3}$ Em terras paraguaias o problema acentuava-se, pois a utilização das parcialidades indígenas que perambulavem pela região como força de trabalho nem sempre foi possível. Muitas viviam errantes pelas matas e montes situados próximos aos rios que integram a Bacia Platina, ou na planíce pampeana, mantendo-se da caça e coleta. "De este genero son los pampas, serranos, charruas, guenoas, guaycurus, mbayas, payaguas y otros en diversas lenguas; $y$ todas ella viven brutalmente, sin conocer à Dios Rey ni ley, enemigos del nombre español, atraidores, haciendo todo el mal que puedan en ciudades, estancias y haciendas (...)" (Pastells, Tomo V, p. 256).

Conhecidos como "índios infiéis", estes nada contribuíram para amenizar o problema da força de trabalho em terras rio-platense. Tão somente era possível contar com a utilização dos guarani ou das parcialidades guaranizadas; estas distinguiam-se das demais por praticarem a horticultura e apresentarem uma conduta semisedentária, sendo identificados por manifestarem certa homogeneidade cultural.

Entretanto a participação dos guarani na esfera social rio-platense deve ser pormenorizada. Podemos indicar a convivência de três realidades guarani distintas nesta sociedade, a saber: o guarani missioneiro, aldeado sob a tutela jesuítica, e disciplinado em várlas modalidades de serviços, sendo este o tipo humano que abordaremos nesta análise. $\mathrm{O}$ outro tipo é o guarani que integrava os "pueblos de indios" e esta sob o controle de outras ordens que não a jesuítica, conhecido como guarani provincial. O último corresponde aos que não estiveram sob o controle de nenhuma ordem, pois "(...) certo número de tribo guaranis tinham escapado dos jesuítas e dos colonos e conservaram a sua autonomia, por que se estabeleceram num território que durante muito tempo permamceu inacessível: daí a denominação de caaiguas ou cainguas (gente da floresta) que lhes foi atribuída" (Clastres, 1978, p. 10).

Estas nuances são necessárias, uma vez que muito da historiografia produzida sobre o período saiu da pena de historiadores comprometidos com a ordem inaciana, resultando, portanto em uma imagem onde todos os guarani do Paraguai eram apresentados sob a tutela jesuítica. Pois a estes importava defender o trabalho da Companhia de Jesus nesta província e apontar o êxito missional desta experiência.

3 "(...) pero falta aqui, como en América en general, trabajadores y labradores" (Müha, 1930, p. 254). 
Apesar de muitos trabalhos apenas exaltarem os feitos missionais levado a cabo pelos jesuítas, é necessário assinalar que houve uma divisão muito acentuada entre as reduções da Companhia de Jesus e os demais "pueblos de indios".

Os guarani disciplinados sob o cajado jesuítico foram gradativamente sendo distanciados do acesso dos "encomenderos". As vezes em que prestavam serviços de guerra - contra o invasor português ou investida de "índios infiéis" - como nos trabalhos prestados nas obras públicas, a decisão final sempre passou pelo crivo dos Procuradores da Companhia de Jesus.

Os jesuítas, sempre buscaram vetar o empréstimo de seus conversos aos interesses partlculares. Quanto ao empréstimo dos guarani missioneiros para prestarem trabalho nas obras públicas, a Companhia acatava os pedidos, mas controlando o fluxo de guarani missioneiros enviados, diferentemente do que ocorria com as demais ordens. Mas nem por isto a presença guarani missioneira foi menos significativa na estrutura social paraguaia.

A importância destas organizações para a sociedade colonial riopla tense ocorria em função de que "(...) en este momento y hasta los inícios de las rebeliones comuneras, los pueblos de indios y las reducciones son - demografica y economicamente - dominante en el marco de esta formación regional" (Garavaglia, 1983, p. 179).

Pelo peso majoritário que apresentavam na região, estes eram os responsáveis pelo fornecimento de alguns gêneros, tais como erva-mate, tecidos, mel, cera e tabaco, só para citar os mais concorridos. Sendo que a execução dos trabalhos mais nefastos - beneficio da erva-mate sempre concorreu por conta dos indígenas recrutados nos "pueblos". ${ }^{4}$ Os guarani aldeados, além de produzirem as principais espécies comercializadas, eram, igualmente, os responsáveis pelo transporte das mesmas: atividade esta que englobava desde a confeccção das carretas ou das embarcações que singravam os rios platinos conduzindo os "frutos de la tierra" ${ }^{5}$ aos mercados interno.

4 "(...) es importante señalar que en ningun momento los pueblos jesuíticos acudieron cumplir con la mita yerbatera". Así lo afirma la fuente más completa de orígen jesuíta, el memorial del padre Francisco Burgues (ca 1705), conforme Garavaglia, 1983, p. 320: nota 128 .

5 "Frutos de la tierra", sẫo gêneros produzidos na América, tais "(...) como es mais, trigo, algodon, gallinas, pescado y otro semejantes frutos y especies (...)" (Manuscritos, 1954, p. 22). 
Por sua vez a inserção da população guarani missioneira na sociedade colonial rio-platense, apresentou alguns matizes que particularizaram-na. A priori os guarani reduzidos pelos jesuítas não possuíam obrigação de prestar serviços públicos, mas deveriam honrar o tributo fixado, após longas discussões, em um peso por cabeça, ${ }^{6}$ tributação devida por sua condição de vassalos do Rei. Mas a baixa monetização da economia colonial, obrigava os jesuítas a orientarem os seus guarani para produzirem gêneros que posteriormente seriam comercializados atráves das Reais Caixas existentes nas capitais de governação; estes recursos visavam saldar o tributo devido e abastecer as reduções com os artigos necessários.

Contudo, muitas vezes a tributação devida findava por ser paga através da prestação de serviços; ${ }^{8}$ uma vez que a Coroa, igualmente, não dispunha de recursos necessários para recompensar os constantes serviços prestados pelos guarani missioneiros.'

O interesse pela numerosa população das reduções guarani jesuíticas, ocorria em função destas congregarem um número significativo de indígenas disciplinados para o trabalho regular e iniciados nas artes e ofícios; que ao executarem uma série de trabalhos nas obras públicas, recebiam o reconhecimento que "(...) en esta ciudad y Prov ${ }^{\text {as }}$, del Rio de la Plata donde V. $\mathrm{R}^{\mathrm{mas}}$ y sus hijos dela compania son lon principales obreros (...)" (Manuscritos, 1970, p. 25) pois desempenhavam papel de

6 Deveria pagar o tributo de um real por ano todo índio do sexo masculino entre $18 \mathrm{e}$ 50 anos, sendo isentos os caciques cabildantes e seus descendentes diretos. Para uma descrição mais pormenorizada, consultar Hernandez Pablo. Organización social de las doctrinas guaranies de la Compañia de Jesus. (Misiones del Paraguay), em especial o capítulo V; Vasallage al Rey: El Tributo.

7 "Las doctrinas de las misiones mantenian constantemente activo comercio con el exterior del territorio, en forma de intercambio de productos, cuyos sob antes eran llevados a vender a las ciudades de Santa Fe y Buenos Aires, en donde hacian al mismo tiempo acopio de materias primas y mercadorias que venian de Europa y que eran necesarias en las Misiones" (Fernandez, 1929, p. 82).

8 Os trabalhos prestados na fortificação de Montevideo, foram "(...) sin sueldo, ni salario, sino solo com el descuento del tributo que debian de pagar". In Fernandez, 1929, p. 116: apud Cattaneo, 1729.

9 "A los Indios se dio el saco atendiendo a $\tilde{q}$ no se divertiesen los Españoles, y sucediesse algun desorden, $\tilde{q}$ no avia peligro en los Indios por ser tantos, $\widetilde{q}$ avia para todo, Y PARA Q ESTOS REZACIESSEN LOS GASTOS DE 6 MESES Q AVIAN ESTADO EN CAMP ${ }^{a}$ SIN COSTERLES AL REY NI UN REAL" II-Relação da $1^{\text {a }}$ tomada da Colônia de Sacramento pelos Espanhóis. "5 XI 1679 a 9 VIII 1680, in Manuscritos, 1954, p. 36. 
destaque no auxílio às cidades coloniais, tanto na sua defesa e manutenção, como no fornecimento de materias-primas, ${ }^{10}$ além da cessão temporária de trabalhadores habilitados nos "ofícios mecânicos".

Esta possibilidede de aproveitamento dos guarani missioneiros ocorreu pois o guarani que aceitava a vida em redução recebia a orientação para a execução de lides domésticas e mecânicas vinculadas à agricultura, pecuária e artesanato. Esta habilitação corria por conta da instrução ministrada pelos jesuítas aos seus neófitos.

A instrução mais especializada era ministrada no pátio dos artesãos, - um conjunto de salas que circundavam um pátio interno - onde eram realizados os trabalhos de carpintaria, funilaria, ferraria, tecelagem, confecção de utensílios em geral e demais ofícios. Este local onde estavam instaladas as oficinas missioneiras igualmente constituia-se no lugar em que eram transmitidos os conhecimentos básicos para os guarani iniciarem-se nos serviços especializados. O jesuíta responsável por sua redução era quem "(...) personalmente les ensinaba quanto era necesario en todos los oficios que en todos dirigia con la destreza que si huviera profesado (...)" (Manuscritos, 1955, p. 180). O aprendizado ministrado aos guarani decorria do ensino pela prática, concorrendo a grande capacidade de observação e imitação ${ }^{11}$ dos guarani para a execução de trabalhos manuais.

Os resultados positivos obtidos ao se habilitar os guarani para a execução de vários ofícios no âmbito missioneiro, despertava o interesse das autoridades coloniais em dispor deste braço disciplinado para o trabalho regular.

Neste quadro regional, as cidades coloniais rio-platenses apresentavam-se como um mercado favorável ao emprego destes guarani, pois "(...) la mano de obra guarani misionera era sumamente valorada y requerida no solo por lo señalado sino también porque ademas de falta de mano de obra fué constante en la Banda Oriental durante todo el período hispanico" (Gonzales, 1989, p. 207).

10 II - Carta do Governador de Buenos Aires, Joseph Martinez de Salazar, para os padres de Companhia de Jesus, e, em especial, das reduções do Paraná e Uruguai, pedindolhes que enviem 300 índios e madeira para auxillar a fortificação de Buenos Aires e a construção de 6 embarcações. Buenos Aires, 29, IX-1663. In Manuscritos, 1954, p. 25.

11 "Los Guaranies fueron excelentes "copistas-escultores" y "copistas-pintores" ségun el mismo P. J. Aguilar, pero faltos de toda creatividad y tambien de una adecuación espontanea. In Susnik, 1979, p. 55. 
Este motivo gerou a presença periódica de guarani missioneiros no perímetro e arredores das principais cidades rio-platenses. Em algumas destas era constante a participação destes indígenas. Pelo menos quatro foram as cidades que seguidamente receberam a incorporação destes guarani a sua paisagem urbana, entre elas destacamos: Buenos Aires - a campeã em requisições - Asunción, Santa Fé e Corrientes. Posteriormente, no segundo quartel do século XVIII em Montevideo, por ocasião da sua instalação. ${ }^{12}$

Além do já mencionado auxílio militar prestado em toda Província, contra todo tipo de invasor, atuavam os guarani missioneiros como espias e informantes ${ }^{13}$ dos governadores. Perspicazes conhecedores ds região, a tudo controlavam com estrema avidez.

Por sua vez os trabalhos prestados nas obras públicas são de grande relevância para a Província como um todo, mas pouco presentes nas análises e bibliografias sobre o período. Esta foi uma das modalidades de serviço prestado em que não contava somente a expressividade numérica, mas destacavam-se os conhecimentos e a habilidade dos guarani empregues nestas tarefas. Trabalhavam como pedreiros, carpinteiros e ferreiros junto as obras de fortificação de várias cidades, ${ }^{14}$ na construção e reparo de catedrais e obras portuárias. Executavam os ofícios de carpinteiro de ribanceira e calafetadores de embarcações, construíndo e consertando as canoas e balsas utilizadas para o transporte

O padre Carlos Cattaneo, refere-se em uma carta datada de 1729, que "los fabricantes son 109 Indios de nuestras Misiones, que vinieron en 1725 (fue principios de 1724) por orden del Gobernador de Buenos Aires, en numero de cerca de dos mil, para fabricar, como lo han hecho hasta ahora, la fortaleza (...) in Hernandez, 1917, p. 71, apud Muratori, 1752. Outro informe bastante expressivo é o Informe al Rey, do mesmo governador Don Bruno Mauricio de Zavala" (...) los que al presente se hallan en Montevideo, estan empleados en hacer la fagina, y transportala para la fortificación que se construye en aquel puerto (...)" in Hernandez, 1913, p. 72, apud Supra, lib I, cap. XIII § VI.

13 "(...) la noticia que ha tenido por los Padres de Compañia de las Misiones de que diversos de sus indios han reconocido a distancia remota de la Colonia dos poblaciones o rancherias de los portugueses (...)". Carta del governador de Buenos Aires, don Bruno de Zabala al Señor Margues de Grimaldo, Buenos Aires, 4 de julio de 1718 in PAST, Tomo VI, p. 170 .

14 Os guarani missioneiros prestaram serviços em várias obras de fortificações, nas governaçōes do Paraguay, Buenos Aires e Tucuman, para nāo tornar demasiado extensa esta nota, consultar Hernandez, Pablo. 1913, p. 68; Capítulo II, parte V: Auxilio en las obras publicas. 
fluvial, ${ }^{15}$ sendo esta forma de transporte de vital importância para o abastecimento dos mercados internos e para a comunicação e defesa das terras provinciais paraguaias.

Estas várias modalidades de serviços prestados pelos guarani missioneiros, são meramente listadas como "auxílio em obras públicas" quando na verdade eram estes os únicos viabilizadores de muitas tarefas essenciais a estas cidades. Os pedidos apenas mencionavam a solicitação de trabalhadores das reduções para as obras a serem realizadas. Mas quando analisamos mais detidamente esta participação nas obras públicas, constata-se que havia uma diferenciação nos serviços executados nestas obras, ${ }^{16}$ o que concorria para a preferência pelo braço guarani missioneiro, por contar com esta especialização. Como o mundo colonial hispânico conviveu sempre com uma precária oferta de oficiais e mestres em várias "artes mecânicas", existindo, inclusive, determinadas a descoberto em certas cidades; somava-se a isto, a natural resistência dos espanhóis aos trabalhos manuais, acentuando ainda mais a baixa especialização do trabalho. A escassa diferenciação existente na divisão do trabalho determinava a pequena distinção entre os executores destes serviços. ${ }^{17}$ Principalmente numa sociedade onde o valor predominante vincula-se ao ócio e desdém aos trabalhos manuais, sendo que "(...) desprecian todas las artes; el que algo entendie y trabaja con gusto, es despreciado como esclavo (...)" (Mühn, 1930, p. 251).

$\mathrm{O}$ interesse pela força de trabalho capacitada nas reduções foi ressaltado diante das dificuldades inerentes a região para arregimentar trabalhadores em grande número, como pela existência de um forte condicionante cultural presente nos colonizadores espanhóis: uma gran-

15 Ver nota 9. Outra informação que contribui para ratificar a participação guarani missioneira nos serviços navais "Los carpinteros indígenas de las misiones jesuíticas conocieron, como decimos, desde muy antiguo las propiedades de los árboles de los bosques milenares de la región guaranítica; sabian muy bien cuãles eran Is más adecuadas para cada construccion" in Adolfo, 1986, p. 169.

16 "(...) nuestros misioneros envian del Paraguay, de tiempo en tiempo algunos albañiles y de otros oficios, los que en servicio del Rey construyen la fortalezas y son cada año mudados por otros". Carta del Hermano Miguel Herre al R. P. Provinvial (Número 438) in Mühn, 1970, p. 252.

17 "Respecto de los trabajadores rurales especializados, es evidente que su proporción es muy baja (...) determinada por la escasa diferenciación en la división del trabajo". In Moreno. Jose Luis. Población y sociedad en el Buenos Aires rural a mediados del siglo XVIII in Desarrollo Economico, V 29, n² 114, (juli-setiembre 1989) p. 272. 
de aversão a realizar trabalhos manuais, excetuando o porte de suas próprias armas.

Muito das dificuldades iniciais enfrentadas pela população rio-platense dizia respeito a necessidade de trabalhadores especializados, problema que estendeu-se por décadas a fio. Pois o velho costume espanhol de desdenhar os ofícios mecânicos, determinou "(...) la necesidad imperiosa que se habían creado los conquistadores, y sus descendientes nascidos en América (unos y otros compreendidos en el titulo de españoles) de tener indios a su servicio: necesidad a que se agregaba la vanidad de considerarse rebajados si hubieran tenido que ejercer por sus propias personas cualquier ministério domestico y aun simplemente si les faltaban número copioso de indios para lucir y aparecer como grandes" (Hernandez, 1913, p. 24).

Neste contexto, as reduções guarani jesuíticas por apresentarem uma iniciação e especialização destes indígenas como trabalhadores capacitados em várias modalidades de ofícios, despertava o interesse das autoridades coloniais em fazer uso deste braço disciplinado para amenizar as dificuldades mais imediatas às principais cidades.

Pelo tom empregado e pela consistência dos argumentos não é difícil deduzir que aos Procuradores provinciais das Missões, não agradava em nada o contato dos guarani minsioneiro com a população espanhola das cidades. Tanto pela influência negativa que poderiam exercer sobre os guarani já conversos, como pela desorganização interna que causava ao sistema produtivo das reduções, que viam suas rotinas alteradas em função do saque de parcela de suas populações.

O empréstimo dos guarani missioneiro para serviços nas obras públicas era periódico, sendo que estes indígenas prestavam serviços por temporadas. A liberação de guaranis para estes serviços era regrada de acordo com as estações do ano.

As atividades econômicas apresentavam uma sincronia com os ciclos da natureza, sendo que a liberação de guarani para prestação de serviço nas obras públicas ocorria preferencialmente nos meses de calor.

Estas prescrições levavam em conta o substrato anterior, pois (...) na sociedade guarani, a maior parte das atividades segue o ritmo sazonal da própria natureza (...) (Arno, mimeo, p. 16). Considerando o conhecimento acumulado dos guarani na região e adequando-os as prioridades coloniais. Os jesuítas logo entenderam a valia da sazonalidade para o melhor aproveitamento do tempo empregue nas atividades rotineiras. 
A Companhia de Jesus, quando atendia aos pedidos de índios para o trabalho, estava flexibilizando sua posição inicial quanto ao empréstimo de seus guaranis ao poder público.

Pois a arregimentação do trabalho indígena por parte do estado colonial foi um dos pilares de exploração desta força de trabalho e por mais que a Companhia argumentasse dos malefícios que os translados de centenas de guarani causariam para a seqüência dos trabalhos missionais, houveram momentos em que foi necessário ceder a pressão das solicitações.

A diferença na relação travada entre a Companhia de Jesus e o poder público colonial, contrastava com o estabelecido com as demais ordens, situação gerada em decorrência da Companhia deter "(...) através de los mecanismos que esta establece que los pueblos participem, sea com sus hombres, sea con sus productos en la realidad economica y politica de la región. Pero sera unicamente la Compañia de Jesus la que especifique el cuando y el como de esta participación (...)" (Garavaglia, 1983, p. 287).

Assim a freqüência com que os guarani missioneiros socorreram a população colonial com serviços, matérias primas ou gêneros, dependeu desta correlação de forças. Ratificando que o papel desempenhado pelos guarani missioneiros, proveniente das reduções jesuíticas, não restringiram-se meramente a pacificação ou guarnecimento dos frágeis limites fronteiriços onde estava inscritos; mas ao fim e ao cabo constituíram-se em centro viabilizador as necessidades mais prementes às cidades coloniais rio-platenses.

As reduções Guarani Jesuíticas podem ter sido ums excrescência quanto ao tipo de inserção que possibilitou ao elemento indígena nos quadros do antigo sistema colonial, mas jamais poderiam manter-se sem contatos com a sociedade onde estavam plotadas, sendo que a própria logevidade e os resultados obtidos pela Companhia de Jesus na região, devem ser analisados dentro deste processo global.

\section{Bibliografia selecionada}

ADOLFO, Hector Cordero. El Primitivo Buenos Aires. $2^{\sharp}$ ediçāo. Plus Ultra. Buenos Aires, 1986.

CLASTRES. Hélène. Terra Sem Mal: o profetismo tupi-guarani. Editora Brasiliense. São Paulo. 1978. 
FERNANDEZ, Ramos Raimundo. Apuntes Históricos sobre Misiones. (Posadas, territorio de Misiones). Madrid, 1929.

FURLONG, Guillermo. Misiones y sus Pueblos de Guaranies. Buenos Aires. Imprenta Balmes, 1962.

GARAVAGLIA, Juan Carlos. Mercado Interno y Economia Colonial. $1^{\text {ta }}$ edição. México. Grijalbo.

_. Ecosistemas y Tecnologia Agrária: elementos para una Historia Social de los Ecosistemas Agrários Rio Platenses (1700-1850) in Desarrollo Economico. Buenos Aires. V: $28 n^{9} 112$, enero-marzo 1989.

GONZALES, Luis Rodolfo Rissotto. La importancia de las Misiones Jesuíticas en la Formación de la Sociedad Uruguaya. in Estudos Ibero-americanos. Porto Alegre, V: XV. № 191-214. Junho 1989.

HAUBERT, Maxime. Índios e Jesuítas no tempo das Missões. São Paulo. Companhia das Letras/Círculo do Livro, 1990. (A vida cotidiana).

HERNANDEZ, Pablo. Organización Social de las Doctrinas Guaranies de la Compañia de Jesus. Barcelona. G. Gili, 1913. 2 vol.

KERN, Arno Alvarez. Missões: uma utopia política. $1^{\text {a }}$ edição. Porto Alegre. Mercado Aberto. 1982.

- Utopias e Missões Guaranis. Porto Alegre: Editora da UFRGS, 1994.

MELIA, Bartoleu. S. J. Missão por Redução in Estudos Leopoldenses. São Leopoldo. Volume 25(110 p. 21-36) maio-junho 1989.

MORENO, Jose Luis. Población y sociedad en el Buenos Aires rural a mediados del siglo XVIII. in Desarrollo Economico V: 29, n² 114 (julio-setiembre 1989).

MÜHN, Juan S. J. El Rio de la Plata por viajeros alemanes del siglo XVIII in Revista del Istituto Histórico y Geografico. Montevideo. 1930, Tomo VII, p. 229 a 325.

MORNER, Magnus. Actividades Politicas y Economicas de los. Jesuítas en el Rio de la Plata. Hyspanemerica Ediciones Argentina. Buenos Aires, 1985.

SUSNIK, Branislava. Los aborigenes del Paraguai - etnohistoria de los guaranies Epoca Colonial. Asunción. Museo Etnografico Andres Barbedo. 1979-1980.

\section{Séries documentais}

A.E.C.B.A - Acuerdos del Extinguido Cabildo de Buenos Aires, serie I y II, publicados bajos la dirección de los Archiveros de la Nación, Jose Biedma y Augusto S. Mallie, Buenos Aires, Tomo I-XVII y I-IX., Buenos Aires, 1907-1930.

A.M.P.A - Annaes do Museo Paulista y Anais do Museo Paulista: "Documentação Espanhola, volumen I, São Paulo, 1925; "Documentos bandeirantes do Archivo General de Indias em Sevilha", volumen V, São Paulo, 1931; "Documentação espenhola do Arquivo de Sevilha", Volumen XIII, São Paulo, 1949.

C.O.B.A - Correspondência de la ciudad de Buenos Aires con los Reyes de España, Tomo II y III, Reunidas en el Archivo General de Indias de Sevilla, coordinada y publicada por R. Levillier, Buenos Aires, 1918. Publicaciones historicas de la Biblioteca del Congreso Argentino. 
C.P.D.E.A - Colección Pedro de Angelis, con prólogos y notas de Andrés Carretero, Editorial Plus Ultra, tomos I-V, Buenos Aires, 1969-1970.

D.O.A.C - Documentos de su Archivo Colonial - Museo Mitre. 1514-1810. Buenos Aires, 1909.

M.D.C.A - Manuscritos da Coleção de Angelis, Tomo IV, Jesuítas e Bandeirantes no Uruguai (1611-1758). Introdução, notas por Helio Viana, Biblioteca Nacional, Divisāo de Obras Raras e Publicações, 1970; Tomo V, Tratado de Madri, - Antecedentes - Colonia de Sacramento. Introdução e notas por Jaime Cortesão, Rio de Janeiro, Biblioteca Nacional, 1954; Tomo VI, Antecedentes do tratado de Madri - Jesuítas e Bandeirantes no Paraguai, (1703-1751). Introdução, notas e sumário por Jaime Cortesão, Biblioteca Nacional, Divisăo de Obras Raras e Publicaçōes, Rio de Janeiro, 1955.

P.A.S.T - Historia de la Compañia de Jesus en la Provincia del Paraguay (Argentina, Paraguay, Perú, Bolivia y Brasil) según los documentos originales del Archivo General de Indias, S. J., Tomos I-V, Madri, 1912-1933; continuada por Francisco Mateos, S. J., Tomos VI-VII, Consejo Superior de Investigaciones Cientificas, Instituto Santo Toribio de Mogrovejo, Madri, 1946-1948.

R.C.P - Reales Cedulas y Provisiones - 1517-1662 - (Archivo de la Nación, Argentina, Epoca Colonial) Buenos Aires, Talleres Gráficos de la Penitenciaria Nacional, 1911, 510 paginas. 